\title{
Orifice Plates to Control the Capacity of Terrace Intake Risers
}

\author{
Jian Hua, James M. Steichen, Bruce M. McEnroe \\ STUDENT MEMBER MEMBER \\ ASAE ASAE
}

\begin{abstract}
6 $T^{\text {he }}$ flow in the conduit from upslope terraces must be controlled so that there is no excess hydraulic head under a lower terrace, causing water to flow up through the riser, which could result in the terrace overtopping" (Schwab et al., 1981). Based upon economic considerations, an orifice plate is used to minimize the conduit size. This experimental study was conducted to evaluate the hydraulic characteristics of different combinations of riser-orifice plate openings.

One open-top and two round-hole terrace intake risers were tested under laboratory conditions using three diameters of orifice plates. The drop-inlet spillway model was used to describe discharge characteristics. Equations and curves were constructed for the head-discharge relationships of various riser-orifice plate combinations.
\end{abstract}

\section{REVIEW OF LITERATURE}

\section{Discharge Through Side Openings}

The flow of water passing through a side orifice can have free discharge, submerged discharge, or partially submerged discharge.

Linderman et al. (1976) studied the field performance of perforated inlet risers in feedlot debris basins. Based on field data, an empirical discharge equation was developed for one particular riser design. This equation indicated that for uniformly spaced side orifices, discharge varied with the 1.43 power of head.

Merrian and Keller (1978) suggested that the orifice discharge coefficient varied from 0.61 to 0.63 for sharp edged orifices drilled in flat plates. Other investigators, such as Beasley et al. (1984), assumed the coefficient of discharge to be approximately 0.6 . In this study, the orifices on the riser were holes or slots perforated on a curved surface instead of a flat surface.

Visser et al. (1988) studied the curved surface in calibrating the discharge coefficient. They used a model with a section of $152-\mathrm{mm}$ (6-in.) cast acrylic tubing, center drilled with a $25.4-\mathrm{mm}$ (1-in.) diameter hole. The discharge coefficient, $\mathrm{c}$, ranged from 0.70 to 0.73 , which is about $20 \%$ larger than the value of 0.6 previously described for a flat surface. Visser et al. (1988) derived equation [1] to determine the discharge capacity at any

\footnotetext{
Article was submitted for publication in August 1988; reviewed and approved for publication by the Soil and Water Div. of ASAE in November 1988.

Contribution No. 88-139-J of the Kansas Agricultural Experiment Station.

The authors are: JIAN HUA, Graduate Student and JAMES M. STEICHEN, Professor, Agricultural Engineering Dept., Kansas State University, Manhattan; and BRUCE M. McENROE, Assistant Professor, Civil Engineering Dept., University of Kansas, Lawrence.
}

given head, H. Any consistent set of units can be used with this equation.

$$
\mathrm{Q}=\frac{2}{3} \mathrm{can} \sqrt{2 \mathrm{~g} \mathrm{H}^{3 / 2}}
$$

where

$\mathrm{Q}=$ discharge

c $=$ orifice discharge coefficient

$\mathrm{a}=$ area of each orifice hole

$\mathrm{n}=$ number of side orifices per unit length

$\mathrm{g}=$ acceleration of gravity

$\mathrm{H}=$ total head, measured outside the riser from bottom of lowest orifice.

A nondimensional depth-discharge relationship for perforated riser inlets with bottom orifices was derived from basic principles by McEnroe et al. (1988).

\section{Discharge Through Drop-Inlet Spillway}

As a starting point of this investigation, the discharge through a drop-inlet spillway was considered. At low heads above the riser, weir flow controls. The vertical transition tube will flow partly full, and weir flow discharge is proportional to $\mathrm{H}^{3 / 2}$. As the discharge over the crest increases and equals the capacity of the conduit inlet, the head will keep rising, and the control will shift to orifice-control flow. The discharge for orifice-control flow is proportional to $\mathrm{H}^{1 / 2}$ (U.S. Department of Interior, Bureau of Reclamation, 1974).

\section{Discharge Through Bottom Orifice Plate}

The discharge through the bottom orifice is similar to the discharge through an opening in the Danïdean tub, as shown in Fig. 1. The free discharge can be determined by

$$
Q=C_{d} A \sqrt{2 g H} \ldots \ldots \ldots \ldots \ldots \ldots
$$

where

$$
\begin{aligned}
& \mathrm{C}_{\mathrm{d}}=\text { the discharge coefficient } \\
& \mathrm{A}=\text { area of orifice } \\
& \mathrm{H}=\text { head. }
\end{aligned}
$$

For the flat-bottom orifice plate, the discharge coefficient, $C_{d}$, is dependent on the coefficient of jet contraction, $\delta$, which is function of the ratio of the orifice diameter to the riser diameter.

Rouse (1946) derived the following relationship for the discharge coefficient of water flowing through an orifice

$$
C_{d}=\frac{\delta}{\sqrt{1-\delta^{2}\left(\frac{d}{D}\right)^{4}}}
$$




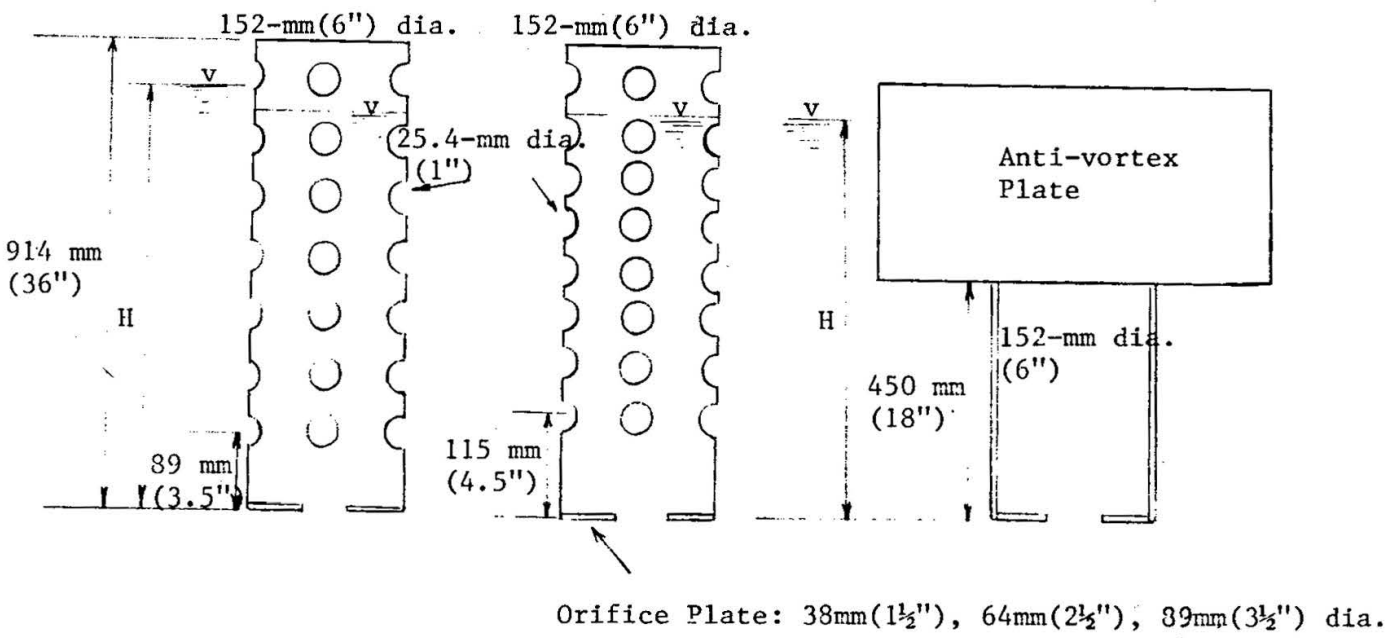

Fig. 1-Schematic of risers.

where

$$
\begin{aligned}
& \mathrm{d}=\text { the orifice diameter } \\
& \mathrm{D}=\text { the inside diameter of the riser. }
\end{aligned}
$$

Based upon the boundary geometry, the discharge coefficient $C_{d}$ has values of $0.620,0.638$ and 0.675 for orifice diameters of $38 \mathrm{~mm}$ (1.5 in.), $64 \mathrm{~mm}$ (2.5 in.) and $89 \mathrm{~mm}$ (3.5 in.), respectively, in a $152-\mathrm{mm}$ (6 in.) diameter riser. The above discharge equation and related coefficients apply, if the orifice is placed at the end of a straight pipe that discharges its jet freely into the air.

\section{PROCEDURE}

The objective of this study was to determine experimentally discharge-head relationships and equations for each of three different types of risers in combination with three sizes of bottom orifice plates.

\section{Risers and Orifice Plates Tested}

Three different risers and three diameters of bottom orifice plates were tested (Fig. 2). All three risers were fabricated from 152-mm (6-in.) diameter, transparent cast acrylic pipe with a wall thickness of $3 \mathrm{~mm}(1 / 8 \mathrm{in}$.). Therefore, the flow inside the riser was visible.

The Type 1 and Type 2 risers were drilled with four 25.4-mm (1-in.) diameter holes per horizontal row. Each row was spaced at $102 \mathrm{~mm}$ (4 in.) and $64 \mathrm{~mm}$ (2.5 in.) for the first and second riser, respectively. Both risers were

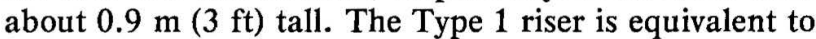
39.4 holes $/ \mathrm{m}$ (12 holes $/ \mathrm{ft})$. The Type 2 riser is equivalent to $63 \mathrm{holes} / \mathrm{m}$ (19.2 holes $/ \mathrm{ft})$. The riser dimensions selected are representative of those used in field installations. The selected dimensions were also limited by the hydraulic capacity of the weir in the return channel.

The Type 3 riser was simply a section of $152-\mathrm{mm}$ (6-in.) diameter, cast acrylic pipe with a length of 450 $\mathrm{mm}$ (18 in.). The top of the riser was open, and there were no side orifices. A commercially manufactured, steel bar-screen was mounted on the top. In addition to maintaining converging flow into the drop inlet, vortex action was minimized. An anti-vortex plate was employed along the crest in order to minimize the effect from fluctuations of the water surface. The anti-vortex plate was a 3 -mm (1/8-in.) thick, aluminum plate with dimensions of $305 \mathrm{~mm} \times 235$ (12 in. x 91/4 in.) mm installed through the bar screen.

The bottom orifice plates were fabricated from a $6-\mathrm{mm}$ (1/4-in.) clear, cast acrylic sheet with outside diameter of $152 \mathrm{~mm}$ (6 in.), and orifice diameters of $38 \mathrm{~mm}$ (1.5 in.), $64 \mathrm{~mm}$ (2.5 in.) and $89 \mathrm{~mm}$ (3.5 in.). In combination with Types 1 and 2 risers, the bottom orifice plates were set with the top of plates depressed $89 \mathrm{~mm}$ (3.5 in.) and $115 \mathrm{~mm}$ (4.5 in.) below the lower edges of the lowest side orifices for Type 1 (102-mm spacing, round hole) and Type 2 (64-mm spacing, round hole) risers, respectively. For the Type 3 (open-top) riser, the same orifice plates used in Types 1 and 2 risers were set $450 \mathrm{~mm}$ (18 in.) below the top edge of the riser.

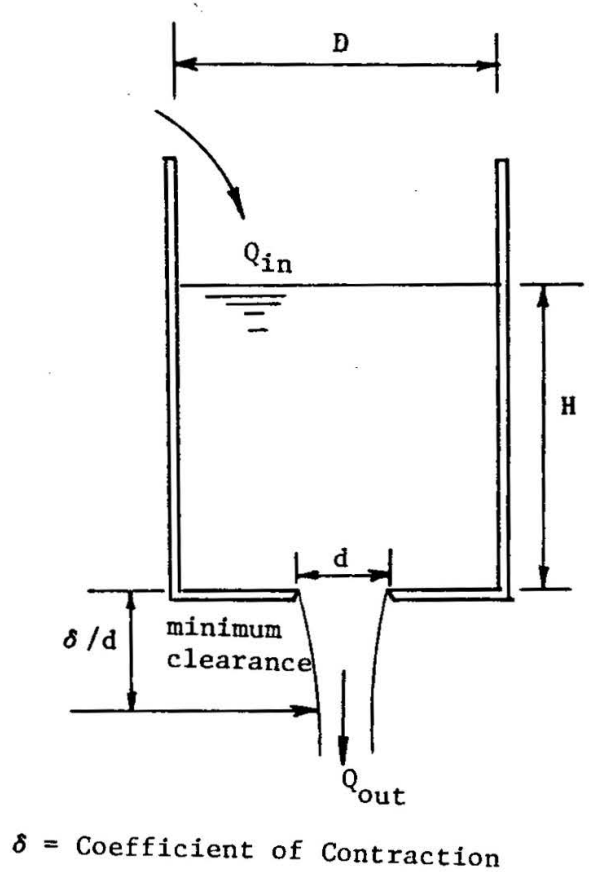

Fig. 2-Description of Danidean tub (after Bos, 1976). 
TABLE 1. Head-discharge relationship for risers without orifice place (in SI)

Equation: $\mathrm{Q}=\mathrm{A} \mathrm{H}^{3 / 2}+\mathrm{C}$

\begin{tabular}{ccccc}
\hline Riser & $\begin{array}{c}\text { Head } \\
\text { range*, } \\
\text { mm }\end{array}$ & A & C & $\mathrm{R}^{2}$ \\
\hline $\begin{array}{c}\text { 102-mm spacing } \\
\text { round hole }\end{array}$ & $27-352$ & 0.0010 & 0.65 & 0.998 \\
\hline $\begin{array}{l}\text { 64-mm spacing } \\
\text { round hole }\end{array}$ & $34-488$ & 0.0019 & 1.3 & 0.999 \\
\hline
\end{tabular}

* Limit use of equations: Equations for risers without orifice plate are obtained based on the assumption that only riser-control flow exists within entire head range tested, as shown in column 2 .

$0=$ discharge, $\mathrm{L} / \mathrm{s}$

$\mathrm{H}=$ head, $\mathrm{mm}$

\section{Head and Discharge Measurement}

The riser head and the V-notch weir head were measured almost simultaneously. Since the flow in the riser was turbulent, the riser's head was measured outside the pipe. It was assumed that all the measurements were made under steady-state flow conditions. Discharge was measured using a 90-deg $V$-notch weir placed in the return channel.

In this study, all three risers were tested first without bottom orifice plates, then they were tested in combination with three different diameters of orifice plates. The head on the bottom orifice plate was defined as the difference in elevation of the water surface outside the riser and that of the upper surface of the circular orifice plate. The elevation of the water surface was measured $0.8 \mathrm{~m}$ upstream of the riser. The head was not measured inside the riser because of the turbulence. The measured heads were not true heads if there was head loss in side inlets. For tests without a bottom orifice plate, head was measured from the bottom edge of the lowest side orifice.

TABLE 3. Head-discharge relationship for risers with orifice plate (SI)

Equation: $Q=A H^{1 / 2}+C$

\begin{tabular}{|c|c|c|c|c|c|}
\hline Riser & $\begin{array}{c}\text { Head } \\
\text { range*, } \\
\text { mm }\end{array}$ & $\begin{array}{c}\text { Orifice } \\
\text { plate } \\
\text { diameter, } \\
\mathrm{mm}\end{array}$ & A & $\mathrm{C}$ & $\mathrm{R}^{2}$ \\
\hline $\begin{array}{l}102-\mathrm{mm} \text { spacing } \\
\text { round hole }\end{array}$ & $\begin{array}{r}215-427 \\
110-778 \\
20-442\end{array}$ & $\begin{array}{l}89 \\
64 \\
38\end{array}$ & $\begin{array}{l}0.89 \\
0.31 \\
0.099\end{array}$ & $\begin{array}{r}-8.65 \\
-0.73 \\
0.33\end{array}$ & $\begin{array}{l}0.997 \\
0.993 \\
0.991\end{array}$ \\
\hline $\begin{array}{l}\text { 64-mm spacing } \\
\text { round hole }\end{array}$ & $\begin{array}{l}95-581 \\
92-559 \\
28-715\end{array}$ & $\begin{array}{l}89 \\
64 \\
38\end{array}$ & $\begin{array}{l}0.70 \\
0.32 \\
0.12\end{array}$ & $\begin{array}{l}-3.69 \\
-0.50 \\
-0.06\end{array}$ & $\begin{array}{l}0.991 \\
0.991 \\
0.980\end{array}$ \\
\hline Open-top & $\begin{array}{l}73-195 \\
49-415 \\
40-284\end{array}$ & $\begin{array}{l}89 \\
64 \\
38\end{array}$ & $\begin{array}{l}0.33 \\
0.21 \\
0.080\end{array}$ & $\begin{array}{l}9.24 \\
4.23 \\
1.54\end{array}$ & $\begin{array}{l}0.973 \\
0.999 \\
0.991\end{array}$ \\
\hline
\end{tabular}

*Limit use of equations: Equations for risers with orifice plate are obtained based on the assumption that orifice-control flow exists within entire head range tested, as shown in column 2 .

$Q=$ discharge,$L / s$

$\mathrm{H}=$ head (outside the riser, not true head above orifice plate), $\mathrm{mm}$
TABLE 2. Head-discharge relationship for risers without orifice place (English)

Equation: $Q=\mathrm{A} \mathrm{H}^{3 / 2}+\mathrm{C}$

\begin{tabular}{ccccc}
\hline Riser & $\begin{array}{c}\text { Head } \\
\text { range*, } \\
\text { in. }\end{array}$ & A & C & $\mathrm{R}^{2}$ \\
\hline $\begin{array}{c}\text { 4-in. spacing } \\
\text { round hole }\end{array}$ & $7.1-14$ & 2.6 & 11 & 0.998 \\
\hline $\begin{array}{c}2.5 \text {-in. spacing } \\
\text { round hole }\end{array}$ & $1.3-19$ & 4.4 & 19 & 0.999 \\
\hline
\end{tabular}

*Limit use of equations: Equations for risers without orifice plate are obtained based on the assumption that only riser-control flow exists within entire head range tested, as shown in column 2.

$\mathrm{Q}=$ discharge, $\mathrm{gal} / \mathrm{min}$

$\mathrm{H}=$ head, in.

\section{RESULTS}

For risers with bottom orifice plates, we observed that at small heads, the discharge was controlled by the riser and was proportional to $\mathrm{H}^{3 / 2}$. As the discharge increased, the control shifted to bottom orifice control, and the discharge was proportional to the square root of the head.

Since the main outlet pipe from test site had a diameter of $254 \mathrm{~mm}$ (10 in.), much greater than the bottom orifice diameter, there was always free outflow. The relationships for each riser-orifice plate combination were determined by regression analyses of discharge versus square root of head within the bottom orifice control range.

The data sets for each combination, therefore, can be described by best-fit equations. The coefficients of determination, $\mathrm{R}^{2}$, were computed to describe how well the equations fit the data. Equations for risers without orifice plates are given in Tables 1 and 2 in SI and custothary units. Equations for risers with orifice plates are given in Tables 3 and 4.

TABLE 4. Head-discharge relationship for risers with orifice plate (English)

Equation: $\mathrm{Q}=\mathrm{A} \mathrm{H}^{\mathbf{1} / 2}+\mathrm{C}$

\begin{tabular}{|c|c|c|c|c|c|}
\hline Riser & $\begin{array}{l}\text { Head } \\
\text { range*, } \\
\text { in. }\end{array}$ & $\begin{array}{l}\text { Orifice } \\
\text { plate } \\
\text { diameter, } \\
\text { in. }\end{array}$ & A & C & $\mathrm{R}^{2}$ \\
\hline $\begin{array}{l}\text { 4-in. } \\
\text { spacing, } \\
\text { round hole }\end{array}$ & $\begin{array}{r}8.5-17 \\
4.3-31 \\
080-17\end{array}$ & $\begin{array}{c}3.5 \\
2.5 \\
1.5\end{array}$ & $\begin{array}{l}8.2 \\
25 \\
7.2\end{array}$ & $\begin{array}{l}19 \\
14 \\
6.5\end{array}$ & $\begin{array}{r}0.997 \\
0.993 \\
0.991\end{array}$ \\
\hline $\begin{array}{l}2.5 \text {-in. } \\
\text { spacing, } \\
\text { round hole }\end{array}$ & $\begin{array}{l}3.7-23 \\
3.6-22 \\
1.1-28\end{array}$ & $\begin{array}{l}3.5 \\
2.5 \\
1.5\end{array}$ & $\begin{array}{l}62 \\
26 \\
8.8\end{array}$ & $\begin{array}{c}-79 \\
-11 \\
2.2\end{array}$ & $\begin{array}{l}0.991 \\
0.991 \\
0.980\end{array}$ \\
\hline Open-Top & $\begin{array}{l}2.8-7.7 \\
1.9-16 \\
1.6-11\end{array}$ & $\begin{array}{l}3.5 \\
2.5 \\
1.5\end{array}$ & $\begin{array}{l}27 \\
16 \\
6.4\end{array}$ & $\begin{array}{r}150 \\
68 \\
24\end{array}$ & $\begin{array}{l}0.973 \\
0.999 \\
0.991\end{array}$ \\
\hline
\end{tabular}

*Limit of equations: Equations for risers with orifice plates are obtained based on the assumption that orifice-control flow exists within entire head range tested, as shown in column 2 .

$\mathrm{Q}=$ discharge, $\mathrm{gal} / \mathrm{min}$

$\mathrm{H}=$ head (outside the riser, not true head above orifice plate), in. 


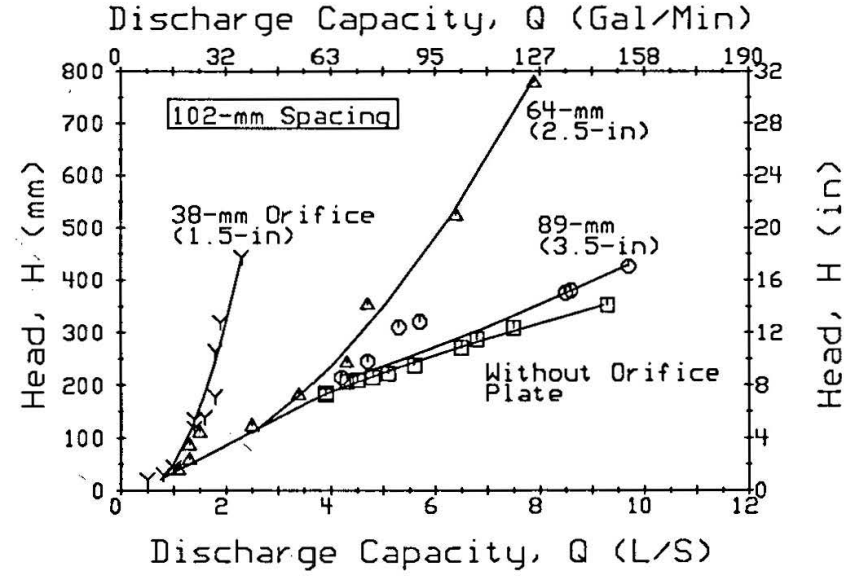

Fig. 3-Head-discharge relationship for 102-mm spacing, round hole riser using different diameters of orifice plates.

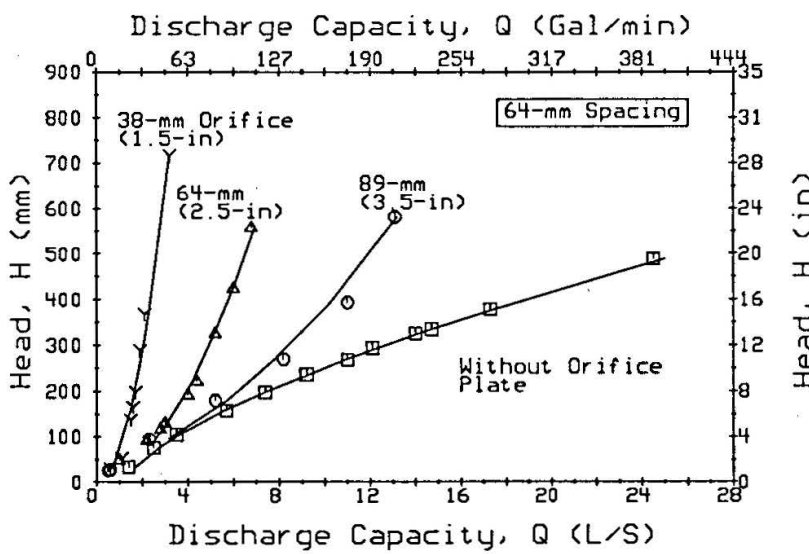

Fig. 4-Head-discharge relationships for 64-mm spacing, round hole riser using different diameters of orifice plates.

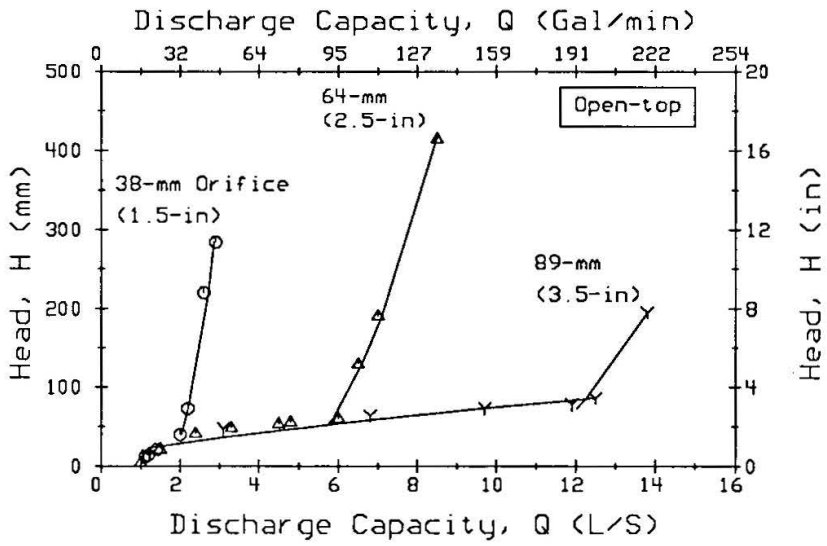

Fig. 5-Head-discharge relationships for open-top riser with bar screen and anti-vortex plate using different diameters of orifice plates.

Based upon the results, the discharge-depth relationships are plotted in Figs. 3 through 5 for each of the four risers without and with the three different sizes of orifice plates. Figures 6 through 8 compare the discharge capacities of the different risers with the same orifice plates.

The head on the circular orifice plate was measured outside the riser. However, this measurement may not be the true head of the orifice plate, since the head outside the riser was definitely greater than the inside head - the true head. Unforunately, the flow inside the riser was

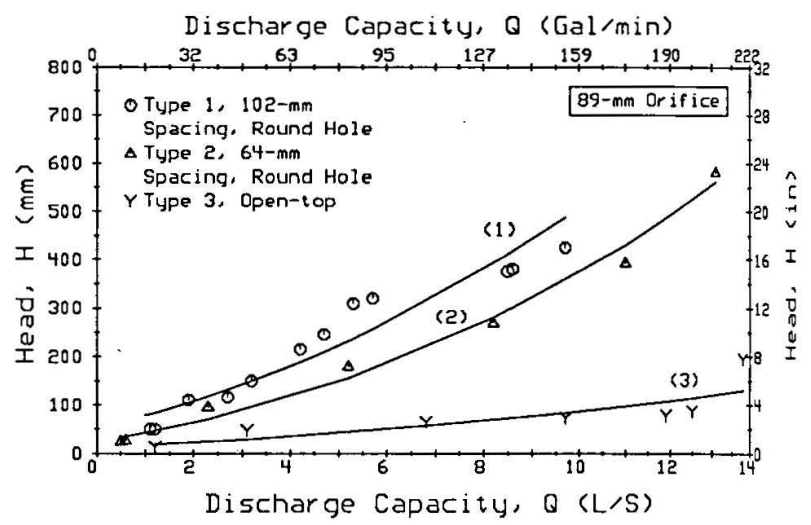

Fig. 6-Discharge comparison for risers with $89 \cdot \mathrm{mm}$ orifice plate.

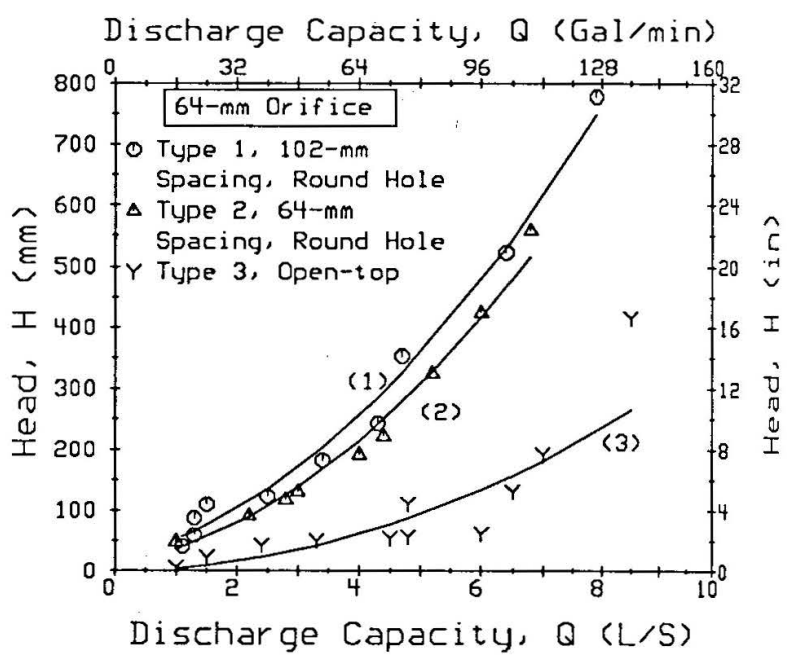

Fig. 7-Discharge comparison for risers with $64-\mathrm{mm}$ orifice plate.

\section{Discharge Capacity, Q (Gal/min)}

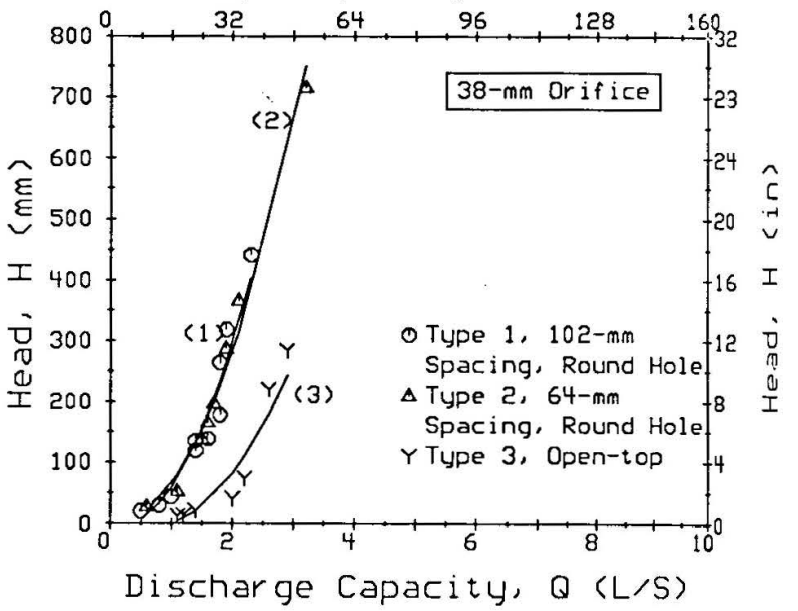

Fig. 8-Discharge comparison for risers with 38-mm orifice plate.

relatively turbulent, and the level was impossible to ascertain directly by measuring with a point gauge. To determine this true head, the pressure head may be determined using a pressure gauge or piezometer.

\section{DISCUSSION}

\section{Regression Equations}

The regression equations constructed for each riser without or with orifice plates were based on hydraulic 
theory. In the beginning, the simulation of the riserorifice combination model was assumed reliable for the drop-inlet spillway. Tables 1 through 4 show the estimated parameters of these equations, range of heads tested, and the coefficients of determination, $\mathrm{R}^{2}$.

First, the regression analyses were performed for Type 1 and Type 2 risers without bottom orifice plates for discharge, $Q$, versus head to the three-halves power, $H^{3 / 2}$. Then, the regressions were run for the data over the orifice-control range for discharge, $Q$, against square root of depth, $\mathrm{H}^{1 / 2}$. Points below the orifice-control range were omitted in these relationships. For these equations, the intercepts (the constant term, C) represented the points at which the flow-shifted from riser control to orifice control.

\section{Weir-Control Flow and Orifice-Control Flow}

In this study of the bottom orifice plates, the headdischarge equations derived were based on a theoretical analysis. From the shape of the head-discharge relationship for all three risers tested in combination with three sizes of orifice plates, the laboratory data supported the hydraulic theory. At low heads, the relationships did follow the no-orifice plate curves, which showed a sharp increase in discharge capacity as the heads increased slightly. With the results obtained from the regression analyses for risers without bottom orifice plates, the $\mathrm{R}^{2}$ values were nearly equal to 1 . Thus, the relationship

$$
Q \propto H^{3 / 2}
$$

was apparent, and the riser controlled the discharge.

As the orifice head increased, the curves diverted upward from different points on the without-orifice-plate curves. This means that there are different points ( $\mathrm{H}$ vs. Q) of transition from riser-control flow to bottom-orificecontrol flow for different sizes of orifice plates. As the flow shifted to orifice control, an increase in head resulted in only a slight increase in discharge, and the relationship

$$
Q \propto \mathrm{H}^{1 / 2}
$$

was noted in this condition.

\section{Comparison of Discharge Capacities}

Figures 6 through 8 show the discharge capacities of Type 1, Type 2 and Type 3 risers in combination with various sizes of orifice plates. The differences are not as significant for the smaller orifice plate as the larger one. For example, when the $38-\mathrm{mm}$ (1.5-in.) orifice plate was used, the discharges of Type 1 and Type 2 risers were fairly close, but the curves deviated when the $89-\mathrm{mm}$ $(3.5$-in.) orifice plate was used. This is because, for a greater discharge, there was a corresponding greater variance of "true-orifice-head" influenced by the greater orifice area.

For the two circular-hole (Type 1 and Type 2) risers without orifice plates, the experimental data were fairly close to the values computed from equation [1]. The discharge coefficient, $\mathrm{C}=0.75$, was somewhat greater than that obtained by Visser et al. (1988). The prediction was more accurate at higher levels measured at the riser. It is suspected that errors were introduced by using the measured riser head, which was not the true orifice head.

\section{Anti-Vortex Plate}

When the Type 3 (open-top) riser was first tested without the bar-screen and anti-vortex plate, a marked vortex surrounding the riser top was induced and continual fluctuation of water level occurred. It was impossible to measure the head-discharge relationship without the antivortex device because of the unsteady flow. This flow variation was diminished when the barscreen was installed onto the riser. The turbulent conditions became more tranquil. However, the fluctuation of water level outside the riser still existed at high discharge. The arbitrarily sized anti-vortex plate was added to yield steady conditions. Field experience with the open-top riser has not identified any problems related to vortex flow.

\section{CONCLUSIONS}

1. Hydraulic laboratory tests of vertical risers for terrace outlets confirmed the theory that the discharge is proportional to the $3 / 2$ power of the depth of flow above the riser with free discharge. With orifices at the bottom of the riser, the discharge is proportional to the $1 / 2$ power of the head above the orifice with free discharge.

2. With a varying head, the transition from weircontrol to orifice-control changes with the inlet area on the riser and the orifice size.

\section{Referentces}

1. Beasley, R. P., J. M. Gregory and T. R. McCarty. 1984. Erosion and Sediment Pollution Control, 2nd ed. Ames: Iowa State Press.

2. Bos, M. G. 1976. Discharge measurement structures. International Institute for Land Reclamation and Improvement. Wageningen, The Netherlands.

3. Linderman, C. L., N. P. Swanson and L. N. Mielke. 1976. Riser design for settling basins. Transactions of the ASAE 19(5):894-896.

4. McEnroe, B. M., J. M. Steichen and R. M. Schweiger. 1988. Hydraulics of perforated riser inlets for underground-outlet terraces. Transactions of the ASAE 31(4):1082-1085.

5. Merriam, J.L. and J. Keller. 1978. Farm Irrigation System Evaluation: $A$ Guide for Management, 3rd ed. Utah State University, Logan.

6. Rouse, H. 1946. Elementary Mechanics of Fluids. New York: John Wiley \& Sons, Inc.

7. Schwab, G. O. et a1. 1981. Soil and Water Conservation Engineering, 3rd. ed. New York: John Wiley \& Sons, Inc.

8. U.S. Dept. of Interior, Bureau of Reclamation. 1974. Design of small dams. Washington, D.C.: USGPO.

9. Visser, K., J. Steichen, B. McEnroe and J. Hua. 1988. Hydraulics of perforated terrace intak risers. Transactions of the ASAE 31(5):1451-1454. 